Foro Interno. Anuario de Teoría Política

ISSN: 1578-4576

http://dx.doi.org/10.5209/FOIN.61509

\title{
Retórica, emociones y pluralismo: déficit democrático en la identidad política del actual independentismo catalán (2011-2017)
}

\author{
Fernando Fernández-Llebrez
}

Recibido: 16 de marzo de 2018 / Aceptado: 10 de mayo 2018

Resumen. El objetivo del artículo es estudiar la identidad política que caracteriza al actual movimiento social y político independentista catalán (2011-2017) desde la teoría retórica de la democracia. La cuestión a analizar será si dicha identidad contiene determinados déficits democráticos que afecten a su inclusividad y pluralismo de tal modo que su capacidad de interacción con una parte significativa de la sociedad catalana quede limitada. Para ello, se comprobará si dicha identidad política es una identidad política común o bien una identidad política parcial porque, en ese caso, y teniendo en cuenta el objetivo que dicho movimiento pretende alcanzar, sus problemas normativos desde un punto de vista democrático serán relevantes.

Palabras clave: Retórica; democracia; identidad política; pluralismo; independencia; Catalunya.

[en] Rhetoric, emotions and pluralism: the democratic deficit in the political identity of the Catalan independence movement (2011-2017)

\begin{abstract}
The objective of this article is to study the political identity that characterizes the current Catalan social and political independence movement (2011-2017) from the rhetorical theory of democracy perspective. The question to be analyzed will be whether this identity contains democratic deficits that affect its inclusivity and pluralism in such a way that its ability to interact with a significant portion of Catalan society is limited. For this purpose, the political identity in question will be examined to determine if it is a common or a partial political identity because, in the latter case its normative problems will be significant, from a democratic perspective, given the goal that this movement aims to achieve.
\end{abstract}

Keywords: Rhetoric; democracy; political identity; pluralism; independence; Catalonia.

Cómo citar: Fernando Fernández-Llebrez, "Retórica, emociones y pluralismo: déficit democrático en la identidad politica del actual independentismo catalán (2011-2017)": Foro Interno. Anuario de Teoría Política, vol. 18 (2018), pp. 27-50.

\section{Introducción}

La cristalización del actual movimiento independentista se dio en 2012, aunque requirió unos antecedentes cercanos que ayudaron a entender por qué ocurrió así. El

\footnotetext{
1 Facultad de Ciencias Políticas y Sociología, Universidad de Granada (España)

E-mail: ffllebrez@gmail.com
} 
sustrato de insatisfacción sobre el que operó el actual movimiento independentista catalán fue un elemento transversal en la sociedad catalana. Sin embargo, la identidad política del independentismo catalán surge posteriormente expresando solo una parte de dicha insatisfacción $\mathrm{y}$, por tanto, con dificultades para recoger una mirada amplia de la sociedad que desea representar.

La tesis de este artículo es que la identidad política que caracteriza al movimiento social y político del actual independentismo catalán contiene determinados déficits democráticos que afectan a su inclusividad y pluralismo. Estos déficits están en su propia concepción y delimitan su capacidad de interacción con una parte significativa de la sociedad catalana. Esta cuestión es relevante para la teoría democrática en tanto en cuanto el objetivo de dicho movimiento es crear un nuevo país y/o un nuevo Estado. La pregunta concreta que vertebrará el artículo es si dicha identidad política es una identidad política común o bien una identidad política parcial porque, en ese caso, y teniendo en cuenta el objetivo que dicho movimiento pretende alcanzar, sus problemas normativos, desde un punto de vista democrático, no serán menores.

La temporalidad a la que se circunscribe el artículo va de 2011, año del nacimiento de la Assemblea Nacional Catalana (ANC), hasta las elecciones de diciembre de 2017, aunque tendrá más peso en el estudio su momento inicial y fundacional.

Este artículo se inserta dentro de la teoría política, pero debido a que pretende analizar una experiencia política concreta se verá abocado a aportar diferentes referencias empíricas que - tomadas a modo de exempla, siguiendo la tradición retórica- permitan contrastar lo dicho. En este ámbito, adquirirá un lugar específico lo planteado por la ANC, debido a la preponderancia que tal asociación ha tenido sobre el conjunto del actual movimiento independentista catalán ${ }^{2}$.

Para entender completamente lo ocurrido dentro del actual independentismo catalán es preciso mirar también a lo hecho y no hecho desde fuera de Catalunya. El positivismo jurídico ${ }^{3}$ en el que se instaló el gobierno español fue un factor relevante para llegar al lugar en el que nos encontramos. Si la propuesta del actual independentismo catalán muestra carencias democráticas, la respuesta dada por parte de las autoridades gubernamentales no se ha quedado corta minimizando la democracia hasta cotas insospechadas. El resultado ha sido un deterioro claro de la calidad de la democracia española en muchos de sus aspectos (jurídicos, políticos, etc) ${ }^{4}$. En un momento de crisis de la democracia lo que se precisaba era ampliarla y desplazarse hacia una mejor democracia, pero no fue así. No obstante, la necesaria atención y amplitud que requiere dicho asunto obliga a tratarlo en un trabajo dedicado exclusivamente a ello y no en este, de ahí que esta segunda cuestión se deje para otro trabajo ${ }^{5}$.

\footnotetext{
Preponderancia que afectará tanto a la dimensión social como política del mismo, pues conviene señalar que dicho movimiento es social y, desde 2012, también político-institucional.

3 Para una conceptualización y crítica a ese positivismo, véase Elías Díaz, "Legitimidad democrática versus legitimidad positivista y legitimidad iusnaturalista", en AA. VV., Anuario de Derechos Humanos, n. ${ }^{1}$, Universidad Complutense de Madrid, Madrid, 1981.

4 Sobre la judicialización del procés, véase Javier Álvarez, "Entrevista": eldiario.es (14-11-2017). Disponible en: https://www.eldiario.es/politica/dirigentes-independentistas-barbaridades-conducta-rebelion_0_707980198.html (1-3-2018).

5 Para un análisis crítico y oportuno sobre la democracia legalista llevada a cabo por el gobierno español, véase Ignacio Sánchez-Cuenca, La confusión nacional. La democracia española ante la crisis catalana, Los Libros de la Catarata, Madrid, 2018.
} 
El artículo quedará dividido en cuatro partes. La primera abordará el marco teórico; la segunda estudiará la sinécdoque propuesta a la hora de denominar al adversario político; la tercera hará lo mismo, pero en referencia a la definición del "nosotros" propuesto; y la cuarta se detendrá en las emociones que caracterizan dicha identidad. Finalmente, se expondrán unas breves conclusiones que las relacionan para una mejor comprensión del conjunto.

\section{Retórica, democracia y pluralismo}

En 2003, Javier Roiz urgía a que la teoría política del siglo veintiuno reabriera los casos del humanismo latino así como de la "tradición retórica de la democracia"6, entendida como el arte del bien decir (ars bene dicendi), con la intención de buscar herramientas y fundamentos teóricos que engrandecieran, mejoraran y ampliaran nuestra concepción de la democracia. Será desde esta perspectiva teórica, y algunas derivaciones indirectas de la misma, desde la que abordaremos nuestro objeto de estudio.

Para esta tradición es preciso recordar que "frente al silogismo que establece sus verdades de forma abstracta y fuera del tiempo, el entinema retórico trabaja teniendo en cuenta las emociones del que escucha y su capacidad libre de juicio. Por eso, la retórica sin libertad sería imposible" . En este sentido, "para tener un buen juicio se necesita contar con los sentimientos y las emociones"8 que nos mueven en cada momento, lo que "convierte a la historicidad del hombre en parte central de la filosofía".

Que se precise tener en cuenta los sentimientos, emociones o pasiones - categorías que, pese a sus diferencias, usaremos de manera indistinta a lo largo de este artículo en aras de facilitar su lectura ${ }^{10}$ - a la hora de pensar la política democrática no significa que la forma en la que estos o estas se estudien tenga que ser unívoca. Qué duda cabe que la retórica puede ser definida y usada de varias maneras y para distintos fines. Puede hermanarse con la "abstracción radical de la política" y, aunque hable de sentimientos, quedar muy alejada del decir de algunos de los afectos de las personas de carne y hueso que componen una sociedad. Cuando es así, "la retórica es un arte lesivo" 11 que queda emparentada con la mentira, la tergiversación y la astucia, cuando no el engaño.

Por el contrario, en la retórica democrática las emociones serán incorporadas a una concepción pedagógica que debe tener un alcance relevante para la preparación del foro democrático, expresando una idea de la democracia en la que está presente "el reconocimiento de los afectos y [de] la ética en el aprendizaje cívico" 12 . Es

\footnotetext{
Javier Roiz, La recuperación del bien juicio. Teoría política en el siglo veinte, Editorial Foro Interno, Madrid, 2003, p. 63.

Ibid., p. 37.

Ibid., p. 44.

Ibidem.

10 Como indica Ramón Máiz, emplearemos como sinónimos estos tres términos, "solo a los limitados efectos de nuestro objetivo en estas páginas". Ramón Máiz, "La hazaña de la razón: la exclusión fundacional de las emociones en la teoría política moderna": Revista de Estudios Políticos, n. ${ }^{\circ} 149$ (2010), p. 13.

11 Roiz, La recuperación del buen juicio, p. 38.

12 Ibid., p. 39.
} 
esta doble presencia la que hace lícito pensar que se pueda establecer algún tipo de relación entre afectos y ética a la hora de elaborar una buena teoría y práctica de la democracia. De este modo, y tomando como punto de partida una perspectiva emotivo-cognitiva $^{13}$, se entenderá que las pasiones actúan sobre nuestros juicios a la vez que estos influyen sobre las emociones pudiendo ser enjuiciadas, y que dicha relación implica "una combinación o una predicación (de un objeto o situación con la idea de bueno o malo) sin pasar por proposiciones que tengan una formulación lingüística"14.

La racionalidad o no de un pensamiento político no vendrá dada por si se usa la razón o la emoción, ya que se pueden encontrar derivas irracionalistas tanto en la una como en la otra. Para salir democráticamente airoso de este envite lo que se requiere es de una buena articulación entre ambas. Lo que se precisa es pensar mejor la democracia para hacerla más democrática, para que su calidad aumente. Como bien precisa Roiz, la tradición de la retórica democrática no pretende suplir la dialéctica por la retórica, sino buscar soluciones "a las necesidades públicas con inventiva, es decir, con saber verdadero y no destructor" 15 .

Esto supone reconocer dos cosas. Por un lado, que la articulación emociones/razones constituye "un necesario concepto explicativo" 16 para la teoría democrática y en concreto a la hora de estudiar "la movilización, la contestación y el conflicto entre proyectos e identidades" $"$. Y, por otro, que es un valioso "concepto normativo que da cuenta de una imprescindible e irrenunciable dimensión de la vida política, precisada de específica evaluación y crítica"18, la cual, cuando no es atendida satisfactoriamente, puede producir lo que Roiz denomina como "política de abandonos"19.

Es verdad que en las identidades colectivas las pasiones tienen un papel destacado de cara a su cementación. También lo es que muchas identidades colectivas se constituyen desde la diferenciación entre un "nosotros" y un "ellos" y que su evaluación o consideración democrática depende de cómo se definan y se relacionen en concreto $^{20}$. Y que es característico del debate democrático el uso habitual de ciertos tropos retóricos. En el caso que nos ocupa, los dos que emergerán serán la sinécdo$q u e^{21}$ y la metáfora, los cuales requieren internamente "la necesaria concurrencia de lo afectivo para que la significación política sea posible"22. La cuestión no es si en la política democrática hay o no sinécdoques o metáforas, ni si en estas operan los afectos, sino su contenido concreto y la manera en la que estos y aquellas se definen.

Seguramente la compleja relación entre la parte y el todo sea una de las grandes cuestiones del pensamiento democrático contemporáneo. Su debate normativo viene

\footnotetext{
13 Véase Martha Nussbaum, Emociones políticas, Paidós, Barcelona, 2014, pp. 175 y ss. Con todo, es preciso hacer una crítica a algunos de los presupuestos de Martha Nussbaum, como su escasa crítica a la vigilancia o el lugar que ocupa la imaginación en la compasión.

14 Ibid., p. 175.

15 Roiz, La recuperación del buen juicio, p. 41.

16 Máiz, "La hazaña de la razón”, p. 42.

17 Ibidem.

18 Ibidem.

19 Roiz, La recuperación del buen juicio, p. 13.

20 Véase Tzvetan Todorov, Los enemigos intimos de la democracia, Galaxia Gutenberg, Madrid, 2012.

21 Entenderemos por sinécdoque la identificación, siempre compleja y problemática, entre las partes y el todo. Véase Quintiliano de Calahorra, Obra completa, Universidad Pontificia de Salamanca, Salamanca, 1996, tomo III, libros VII-IX, p. 249.

22 Máiz, "La hazaña de la razón”, p. 40.
} 
de lejos y tiene una literatura procelosa que va desde los planteamientos de Jean-Jacques Rousseau (1712-1778) a los de Jeremy Bentham (1748-1832) pasando por John Stuart Mill (1806-1873), entre otros. Y llega hasta hoy en día con la obra de Chantal Mouffe, Martha Nussbaum o Seyla Benhabib, entre otras.

Pero desde la Segunda Guerra Mundial hay un significativo acuerdo a la hora de abordar dicha cuestión que pasa por la defensa del pluralismo como elemento vertebrador de las diferencias. Tal y como han reconocido diferentes autores y desde distintas perspectivas, el pluralismo es un elemento imprescindible para la caracterización de las democracias actuales en aras del reconocimiento de un todo que nunca es homogéneo dado que el conflicto y la diferencia es constitutiva del propio sujeto democrático ${ }^{23}$.

Toda reflexión sobre el pluralismo democrático supone una forma de acercarse a la relación que hay entre la libertad política y la libertad individual. En la tradición del humanismo latino son claves las referencias hechas a este respecto por Quentin Skinner. Como señala Mouffe, que en esto sigue a Skinner, "la tarea principal de la teoría política democrática moderna es la articulación de libertad individual y libertad política, siendo allí donde hunde sus raíces la cuestión del pluralismo y la ciudadanía democrática" 24 . Esto implica que una teoría democrática moderna debe ser capaz de "formular el carácter ético de la ciudadanía moderna de tal modo que sea compatible con el pluralismo moral" 25 . Lo que nos hace ciudadanos de un sistema democrático son un conjunto de principios políticos específicos democrático liberales entre los que está el pluralismo, aunque este es, a su vez, el vector que también posibilita el reconocimiento de los restantes.

Este concepto de ciudadanía implica atribuirle un estatus legal ineludible e imprescindible, pero también reconocerle una dimensión cultural (o político cultural) que, yendo más allá de ese estatus, le da sentido político a la comunidad cívica en la que se habita; es una forma de identidad política común que reconoce una pluralidad de lealtades que afectan a la libertad individual y a las diferentes identidades colectivas que deambulan por la sociedad, lo que la diferenciará de lo que comunmente se califica como "políticas de identidad"26.

Esto supone apelar a determinados valores entre los que destaca el reconocimiento o la inclusión del otro como una parte característica de los lazos que se fraguan entre los participantes de una asociación política - como la que conforma, por ejemplo, un Estado y/o un país - . El pluralismo democrático sostiene una forma de asociación de la que, dejando espacio a la libertad individual, "se puede gozar entre

23 Para la cuestión del pluralismo, acúdase a Michael Walzer, Pensar políticamente, Paidós, Barcelona, 2010, pp. 131 y ss; Chantal Mouffe, El retorno de lo político, Paidós, Barcelona, 1999, pp. 62 y ss; Norberto Bobbio, The future of Democracy, Polity Press, Cambridge, 1987, pp. 25 y ss.

24 Mouffe, El retorno de lo político, pp. 62 y 63.

25 Ibid., p. 96.

26 Como indica Mary Kaldor la identidad política no es lo mismo que la "política de identidad" y en concreto se contrapone a "la nueva política de identidades [que] consiste en reivindicar poder basándose en etiquetas" que tienden a la fragmentación y la exclusión. Citado por Jon Juaristi, "Identidad política y política de identidades": Letras libres, n. 5 (2002), p. 42. Para una crítica a las políticas de identidad, véase Fernando Fernández-Llebrez, "Democratización de las identidades, transgenerismo y malestares de género": Desafios, vol. 27, n. ${ }^{\circ} 2$ (2015), pp. 99-143. Para una aproximación a la construcción de la identidad española, véase, entre otros, Jordi Muñoz, La construcción política de la identidad española, CIS, Madrid, 2013; y José Álvarez Junco, Mater dolorosa, Taurus, Madrid, 2017. 
personas relativamente extrañas que pertenecen a muchas asociaciones" 27 y cuyas respectivas lealtades a grupos específicos no debe entrar en contradicción con su pertenencia a la asociación civil.

Pero no conviene olvidar que si de lo que se está hablando es de la creación de una identidad política común en una sociedad democrática son imprescindibles varias cuestiones.

Por un lado, esta identidad política común estará sujeta a la contingencia de la vida por lo que no cabe pensarla como una solución definitiva ni para siempre. Y a la par, la propia diferencia hará que no pueda abarcar literalmente la totalidad, de ahí que el ejercicio de la sinécdoque sea un recurso habitual para su formulación.

Por otro lado, dicha identidad no podrá venir cargada ni de dicotomías dialécticas - que imposibilitan la puesta en común, pues solo cabe elegir entre lo uno o lo otro- ni de esencias que hagan imposible su mutación o cambio. Todo encuentro inclusivo entre diferentes partes supone algún tipo de modulación. La necesaria crítica a las esencias, así como a la dicotomización, hace que las teorías románticas, y la dialéctica que las caracteriza, no sean buenos acompañantes para este viaje porque de lo contrario difícilmente será una identidad ampliamente compartida.

Y por último, la heterogeneidad tendrá que ser reconocida no solo fuera de sí misma (exterior constitutivo), sino también en su propio seno - lo que podríamos denominar como su interior constitutivo - y que, como tal, ha de formar parte - aunque sea parcialmente - de esa identidad común. Para que dicha identidad política sea común y pluralista se requiere reconocer ese interior constitutivo en las sociedades democráticas porque, de lo contrario, no habrá pluralismo democrático en su interior, sino la mera concatenación, ya sea vía cohabitación o imposición, de diferentes identidades (parciales).

De este modo, se podría decir que una ciudadanía democrática y pluralista al unir - aunque no sea completamente- a personas relativamente extrañas hace que los conciudadanos de un determinado territorio no se sientan extranjeros en su propia sociedad.

Será la manera concreta en la que se defina una identidad política democrática la que hará que esta sea común y pluralista o, en su defecto, parcial y no pluralista. Precisamente por esto es por lo que nuestra reflexión no pretende ser un análisis de toda identidad, ni de todo nacionalismo, ni de todo independentismo, ni de todo el procés catalán, sino que partiendo de una experiencia determinada estudia una de sus facetas más relevantes como es su identidad política.

Desde este marco normativo democrático será desde el que se analizará la concreta formación y definición de la identidad política en el actual independentismo catalán (2011-2017) y, en concreto, en la ANC como uno de sus significativos referentes.

\section{La sinécdoque exterior: sobre esencias y dicotomías}

El discurso que caracteriza a la ANC supone una forma determinada de abordar la identidad política que va a definir al movimiento independentista. Como manifestaba de manera autoreferencial la ANC en 2012: la estrategia del movimiento

27 Mouffe, El retorno de lo politico, p. 98. 
independentista "se define en los puntos aprobados por la Conferencia Nacional por el Estado propio" 28 , la cual no se modificará a lo largo de los cinco años venideros.

Esta identidad política se expresará a través de la típica diferenciación entre un "nosotros" (la nación o el pueblo catalán) y un "ellos" (España), lo cual no es ninguna novedad. Lo característico será la forma concreta en la que lo hace.

El sustrato sobre el que va actuar la ANC es la insatisfacción con el proceso autonómico. A modo de ejemplo, cabe señalar que en junio de 2011 el grado de insatisfacción de una parte de la sociedad catalana con el proceso autonómico era del $66,5 \%$. Un año más tarde se situaba todavía más alto $(68,4 \%)$ y en octubre de 2012 superó la barrera del $70 \%$ (71,6 \%), quedando solo por encima de ese valor el índice de junio de $2013^{29}$. Hablamos de momentos de cifras record de esta insatisfacción que siempre ha estado presente durante todo el procés y que, en ese momento, adquiere una fuerza enorme como contexto de recepción ${ }^{30}$. La ANC, en su Declaración Fundacional, se hace eco de esta realidad cuando señala "que la opinión pública de Cataluña se manifiesta mayoritariamente insatisfecha con el grado de autonomía y de capacidad de decisión que disfrutan los catalanes" ${ }^{\prime 3}$. Sobre este malestar, la ANC postuló ciertas ideas que dieron sentido político y emocional a su identidad política. Bien podían haber cristalizado otras, aunque las únicas que se activaron fueron las provenientes del mundo independentista.

Desde un primer momento, la ANC dejaba claro que España era incapaz de atender la realidad nacional catalana, siendo contraria al desarrollo de Catalunya como nación. Para justificar esta perspectiva el independentismo fijó una idea esencialista de España. Para la ANC "lo que nos proponen desde España"32 es la misma idea de siempre, que no cambia ni puede hacerlo, siendo imposible que se pueda desprender de ella. Una tesis sobre la irreformabilidad de España que será constitutiva de su discurso.

En la Hoja de Ruta de 2013 se afirmará que "la historia demuestra que todos los gestos hacia Cataluña, o han sido de hostilidad o de indiferencia, o son falsas propuestas hechas exclusivamente para calmar situaciones coyunturales de descontento o de reivindicación general en Catalunya" ${ }^{33}$. Y se concluirá con que "Catalunya es tratada [por parte de España] como una colonia, según la lógica del derecho de conquista" 34 .

28 “És definida en els punts aprovats per la Conferència Nacional per l'Estat propi”. Assemblea Nacional Catalana, Full de Ruta 2012: Línies estratègiques i propostes d'actuació, Barcelona, 10 de marzo de 2012, p. 5. Disponible en: http://ipaz.ugr.es/wp-content/uploads/2018/05/3.-Full-de-Ruta-2012-marzo-10..pdf (1-3-2017).

29 Pregunta 29: “Creu que Catalunya ha assolit...". Centre d'Estudis d'Opinió (CEO), Baròmetre d'Opinió Política, 1 onada 2017, Generalitat de Catalunya, Barcelona, 2017. Disponible en:

http://ceo.gencat.cat/ca/barometre/detall/index.html?id=6168 (1-3-2018).

30 Entendemos por "contextos de recepción" las situaciones en las que se percibe un texto - o un discurso (speech) — que influye de manera importante en su interpretación. Teun van Dijk, "Algunos principios de una teoría del contexto": Revista Latinoamericana de Estudios del Discurso, vol. 1, n. ${ }^{\circ} 1$ (2001), pp. 69-81.

31 “Que l'opinió pública de Catalunya es manifesta majoritàriament insatisfeta amb el grau d'autonomia i de capacitat de decisió de què gaudeixen els catalans". Assemblea Nacional Catalana, Declaració de la Conferèrencia Nacional per l'Estat propi, Barcelona, 30 de abril de 2011, p. 1. Disponible en:

https://assemblea.cat/index.php/documents/(15-9-2018).

32 "Els que es proposen des d'Espanya". Ibidem.

33 "La història demostra que tots els gestos cap a Catalunya, o han estat d'hostilitat o d'indiferència, o són falses propostes fetes exclusivament per calmar situacions conjunturals de descontentament o reivindicació general a Catalunya". Assemblea Nacional Catalana, Full de Ruta 2013: Full de Ruta aprovat en l'Assemblea General del 16 de març de 2013, Girona, 16 de marzo de 2013, p. 3.

34 "Catalunya és tractada...com una colònia, segons la lògica del dret de conquista". Ibidem. 
En 2012, en la primera Hoja de Ruta que se confeccionó como tal, se insiste en ello cuando se afirma que:

La vía autonómica iniciada con la transición democrática, no solo no nos permite avanzar en la reconstrucción nacional, sino que, lo que es aún peor, nos hace retroceder, conduciéndonos inexorablemente a la desaparición de nuestra cultura, de nuestra lengua y, en definitiva, de la nación catalana. Este proceso nos lleva, también, al empobrecimiento económico e intelectual de toda la sociedad catalana, tanto a nivel individual como a nivel colectivo ${ }^{35}$.

Tal concepción sobre España y su esencia histórica ya venía definida en la Declaración Fundacional de 2011 donde la nación española se concibe como un proyecto que:

Bajo la apariencia de modernidad, mantiene los objetivos unificadores y homogeneizadores castellanos que siempre la han caracterizado. [De ahí que] después de más de treinta años, el modelo autonómico español demuestre ser incapaz de responder a nuestras expectativas de autogobierno. Este fracaso se ha producido, entre otras razones, porque no ha sido un modelo fundamentado en el respeto a la realidad plurinacional y plurilingüe, y porque ha creado estructuras sociales, culturales, administrativas y económicas contrarias al desarrollo de la nación catalana $^{36}$.

Para este relato, su constatación mayor y definitiva será la sentencia del Tribunal Constitucional de 2010 $0^{37}$; momento y fecha que será incorporada, desde el inicio, como emblema del relato independentista. Más allá de la veracidad de dicho emblema, el cambio en el relato fue lo suficientemente eficaz como para ser un lugar desde el que el independentismo fuera creciendo.

La idea obsoleta y homogénea de España postulada supone un ejercicio de abstracción nada desdeñable que choca con los cambios acaecidos, aun con todos sus límites, en la sociedad y democracia española - incluida la catalana - en estos últimos cuarenta años y que afectan al proceso democratizador que se ha venido dando. Es un razonamiento descontextualizado y mítico, en donde no se habla de personas de carne y hueso con sus deseos, sueños y emociones, y que saca a una realidad plural y compleja de sus propios avatares en aras de una esencia que, por ser tal,

35 "Que la via autonòmica iniciada amb la transició democràtica, no només no ens permet avançar en la reconstrucció nacional, sinó que, el que és encara pitjor, ens fa retrocedir, conduint-nos inexorablement a la desaparició de la nostra cultura, de la nostra llengua i, en definitiva, de la nació catalana. Aquest procés ens porta, també, a l'empobriment econòmic $\mathrm{i}$ intel·lectual de tota la societat catalana, tant a nivell individual com a nivell col·lectiu". Assemblea Nacional Catalana, Full de Ruta 2012, p. 3.

36 "Que, sota l'aparença de modernitat, manté els objectius unificadors i homogeneïtzadors castellans que sempre l'han caracteritzada... Després de més de trenta anys, el model autonòmic espanyol demostra ser incapaç de respondre a les nostres expectatives d'autogovern. Aquest fracàs s'ha esdevingut, entre d'altres raons, perquè no ha estat un model fonamentat en el respecte a la realitat plurinacional i plurilingüística, i perquè ha creat estructures socials, culturals, administratives i econòmiques contràries al desenvolupament de la nació catalana". Assemblea Nacional Catalana, Declaració de la Conferèrencia Nacional per l'Estat propi, p. 1.

37 "Esta situación, definitivamente aclarada, desde la óptica española, por la sentencia del Tribunal Constitucional español de 28 de junio de 2010" (“aquesta situació, definitivament aclarida, des de 1'òptica espanyola, per la sentència del Tribunal Constitucional espanyol de 28 de juny de 2010 ”). Ibidem. 
es indemostrable y que, como tal, es inamovible. Cabe lícitamente pretender más autogobierno, pero una cosa es esa legítima pretensión y otra las conclusiones que se infieren en este concreto razonar, según el cual, España ha ido contra Catalunya como realidad política y cultural.

Por ejemplo, que sea cierto que no haya en la actual Constitución española un reconocimiento jurídico expreso de la plurinacionalidad, en tales términos, aunque sí en los de "nacionalidad histórica" 38 , no significa que se hayan construido estructuras contrarias a la nación catalana, ni que no haya en España un reconocimiento político de la identidad cultural y política de Catalunya como país. Y menos aun que no la pueda haber jurídicamente en un futuro. No solo la expresión política y cultural de "nación de naciones" forma parte de dicho bagaje ${ }^{39}$, sino que el grado de reconocimiento político y competencial de Catalunya es bastante significativo en la España actual ${ }^{40}$. O por acudir a experiencias aun más recientes y que afectan a otras cuestiones: ¿cómo explicar el surgimiento del $15 \mathrm{M}$ o del movimiento contra la guerra de Irak o la universalización de la sanidad pública y de la educación o la defensa de determinadas libertades sexuales y de igualdad entre los géneros si la España de hoy es la España de siempre que dicha identidad política pretende reflejar? ${ }^{41}$.

No obstante, clamar esta idea esencialista de España, que la identifica con un halo autoritario, no es una novedad. Pero sí que lo fue el ejercicio de sinécdoque en el que se apoyó para que tal idea se pudiera fijar más fácilmente en el imaginario social. El actual independentismo catalán aprovechó una situación concreta de crisis económica y política, así como la llegada al gobierno del PP, con la intención de establecer una idea de España periclitada y petrificada ${ }^{42}$ confundiendo lo que puede significar un gobierno o unas políticas determinadas ciertamente inmovilistas - la parte - con España y su democracia —el todo-. De ello se hizo eco la propia ANC en 2012 cuando señalaba que: "la victoria del PP en las elecciones al Parlamento español puede suponer también un factor acelerador o potenciador"

En este ejercicio de sinécdoque no solo se identificaban esencias culturales e identitarias. También adquirirá fuerza el aspecto económico. Los males económicos de Catalunya se explicarían por la relación con España que imposibilita su expansión económica y que quedan reflejados en la sustracción económica — expolio fiscalque España, vía financiación, produce en Catalunya. Como se indica en la Hoja de Ruta de 2012, entre las razones para la independencia están "las relacionadas con el expolio fiscal al que nos somete el Estado español [que nos afecta] a todos los ciuda-

38 Pues depende de cómo se defina el término nación. Para este menester véase, Alberto López Basaguren, "Hablemos (de nuevo) de nación": El Correo (27-11-2016), p. 2. Disponible en:

http://www.pensamientocritico.org/alblop1216.pdf (15-9-2018).

39 Véase Anna Ma García Rovira (ed.), España, ¿nación de naciones?, Serie Ayer, 35, Marcial Pons, Madrid, 1999.

40 Véase Santiago Muñoz Machado, Informe sobre España, Crítica, Barcelona, 2014.

${ }^{41} \quad$ ¿Y cómo maridar esa supuesta España de siempre con la iniciativa social “\#Hablamos?” que consiguió amplísimas concentraciones de personas a lo largo del país? Véase Enric Juliana, "La España de los pingüinos": $L a$ Vanguardia (8-10-2017). Disponible en:

https://www.lavanguardia.com/opinion/20171008/431878716908/la-espana-de-los-pinguinos.html (1-3-2018).

42 Imagen que concuerda con lo señalado por Silvina Vázquez en su estudio Identidad nacional y autogobierno. Un estudio cualitativo sobre las configuraciones identitarias nacionales en la Cataluña contemporánea, Monografies, Centre d'Estudis d'Opinió (CEO), Generalitat de Catalunya, Barcelona, Julio 2013.

43 "La victòria del PP en les eleccions al Parlament espanyol pot suposar també un factor accelerador o potenciador". Assemblea Nacional Catalana, Full de Ruta 2012, p. 4. 
danos catalanes" ${ }^{\prime 4}$. Un expolio económico que se relaciona con el trato desigual que recibe Catalunya respecto a otras Comunidades Autónomas. Como vuelven a recordar en la Ponencia Marco de 2015, hay que "tener presente que la crisis económica y financiera hará aún más evidente la diferencia de trato del Gobierno en Catalunya en comparación con otros territorios del Estado español" 45 .

Esta no contrastada reflexión sobre el "expolio" fiscal será conectada con la cuestión del pacto fiscal que se estaba debatiendo en ese mismo tiempo, mostrando el valor instrumental que tendrá dicha cuestión para el objetivo pretendido. Así, en 2012 la ANC señalará que "es necesario que el gobierno catalán acelere el proceso negociador, no afloje en sus posiciones ni nos quiera hacer ver lo que no es...La ANC debe enmarcar el pacto fiscal en el camino hacia la consecución del Estado propio"46.

En un sentido similar se había expresado la ANC en 2011 cuando afirmaba que:

El Estado no apoya a los habitantes de Cataluña y perjudica notoriamente sus posibilidades de mantener e incrementar el nivel de vida y bienestar social que la capacidad productiva e intelectual del país permitiría, disminuyendo y limitando conscientemente las potencialidades de nuestro desarrollo económico y social ${ }^{47}$.

Una situación de destrucción económica que iba acompañada de un "genocidio cultural" 48 por parte de España que generaba una constante desafección y ánimo en la población catalana que solo hacía posible dos salidas: o la definitiva integración en el proyecto homogenizador que siempre ha caracterizado a España "o el inicio de un proceso de independencia que nos lleve a la constitución de un Estado propio"49.

Como era de prever en un razonamiento esencialista, las realidades no pueden modularse porque si no no se darían tales esencias. La forma de presentar el problema debe reflejar una concepción dualista y dicotómica en la que solo caben dos soluciones (o dentro o fuera) ya que la única manera en la que una perspectiva esencialista puede entender el conflicto y la diferencia es la que se da entre contradictorios (esto es, tertium non datur). Es por ello por lo que no caben opciones "intermedias" (es decir, tertium datur) siendo imposibles terceras posibilidades. De ahí que para el independentismo la cuestión sea $u$ homogenización y pérdida del sentido de la catalanidad $o$ la creación de un Estado propio independiente.

Este ejercicio de sinécdoque, sustentado en postulados esencialistas y dicotómicos, hace que la irreformabilidad de España afecte a su totalidad y no a algunas de sus partes; y por ello que la pertenencia de Catalunya en España implique, necesariamente, la negación de la nación catalana (en cuanto a lengua, cultura, economía,

44 "Les relacionades amb l'espoli fiscal al que ens sotmet l'Estat espanyol.... a tots els ciutadans Catalans”. Ibid., p. 7.

45 "Tenir present que la crisi econòmica i financera farà encara més evident la diferència de tracte del Govern espanyol a Catalunya en comparació amb altres territoris de l'Estat espanyol'. Assemblea Nacional Catalana, Assemblea General ordinaria 2015. Ponència Marc (2015-2016), Lleida, 12 de abril de 2015, p. 7.

46 "Cal que el govern català acceleri el procés negociador, no afluixi en les seves posicions ni ens vulgui fer veure el que no és...L'ANC ha d'emmarcar el pacte fiscal en el camí cap a la consecució de l'Estat propi”. Assemblea Nacional Catalana, Full de Ruta 2012, p. 8.

47 'L'Estat no dóna suport als habitants de Catalunya i perjudica notòriament les seves possibilitats de mantenir $\mathrm{i}$ incrementar el nivell de vida i benestar social que la capacitat productiva i intel·lectual del país permetria, disminuint i limitant conscientment les potencialitats del nostre desenvolupament econòmic i social". Assemblea Nacional Catalana, Declaració de la Conferèrencia Nacional per l'Estat propi, p. 1.

48 "Genocidi cultural". Ibidem.

49 “O l'inici d'un procés d'independència que ens porti a la constitució d'un estat propi”. Ibidem. 
etc.), dándose una relación de inconmensurabilidad entre ambas. Así, quien quiera defender a Catalunya tiene que terminar queriendo irse de España. Si Catalunya y España son dos realidades que no tienen nada o poco que ver entre sí, entonces, tener esa idea esencialista de España, ser independentista y "defender Catalunya" se convierten, para este discurso, en vocablos sinónimos.

Este juego de identificaciones es el que permite sacar fuera de Catalunya todo aquello que pudiera calificarse como negativo. Debido a este concreto ejercicio de sinécdoque lo que se contrapone son dos todos: uno con el que no merece la pena identificación alguna - la España irreformable-, y otro del que poderse sentir orgulloso - la nación catalana ${ }^{50}$.

Una vez visto como se fija y se distancia del adversario, es preciso preguntarse por la idea de Catalunya — o de nación catalana — que esta identidad política postula.

\section{La sinécdoque interior: parcialidad y homogeneidad}

Si bien las referencias que caracterizan su modelo cultural y político para Catalunya son etéreas y generales, sí que se pueden encontrar tres ideas claves que vertebran su discurso.

En primer lugar, la sociedad catalana queda identificada con una determinada forma de entender la cultura catalana. En la Declaración Fundacional de la ANC de 2011 se hace una apelación a "la comunidad de lengua, de cultura, de derecho, de tradiciones y con una estructura social y económica similar" ${ }^{\prime \prime}$ que es Catalunya. En 2013 se concreta más cuando se afirma que la singularidad de la nación catalana "se fundamenta en la voluntad colectiva de ser, en su identidad cultural y en el catalán como lengua común de nuestro país, así como del occitano-aranés en el Valle de Arán, sin perjuicio del respeto para las otras lenguas que estén presentes" ${ }^{2}$. Esta diferenciación entre la lengua común (el catalán) y las otras lenguas expresa una jerarquización a la hora de definir su identidad que no reconoce la pluralidad lingüística en términos de igualdad.

En segundo lugar, la sociedad catalana se presenta como una sociedad homogénea caracterizada por una "voluntad colectiva de ser". La sociedad catalana se encontraría unificada en torno a un único objetivo común como es el deseo de ser un Estado independiente. De hecho, es el único futuro posible. Según reza en la Hoja de Ruta de 2012: la sociedad catalana está "más unida que nunca en torno a la independencia como único futuro posible"53. Un único futuro que queda inexorablemente relacionado con la defensa de la nación catalana pues "este objetivo es inherente a la condición de nación" 54 ; de ahí que se afirme que "la condición de nación va em-

50 Para un ejemplo reciente de ello, véase Jordi Graupera, "El desbordamiento": El Nacional.cat (17-2-2018). Disponible en: https://www.elnacional.cat/es/opinion/jordi-grauper-el-desbordamiento_240057_102.html (1-3-2018).

51 "La comunitat de llengua, de cultura, de dret, de tradicions i en una estructura social i econòmica semblant". Assemblea Nacional Catalana, Declaració de la Conferèrencia Nacional per l'Estat propi, p. 1.

52 "Es fonamenta en la voluntat col-lectiva de ser, la seva identitat cultural i el català com a llengua comuna del nostre país, així com de l'occità-aranès a l'Aran, sense perjudici del respecte per a les altres llengües que hi són presents". Assemblea Nacional Catalana, Full de Ruta 2013, p. 3.

53 "Més unida que mai entorn de la independència com a únic futur possible". Assemblea Nacional Catalana, Full de Ruta 2012, p. 3.

54 “Aquest objectiu és inherent a la condició de nació". Ibid., p. 7. 
parejada con tener un aparato de Estado" 55 , siendo ya solo posible defender "que el Estado propio es la mejor herramienta para conseguir mayores cotas de bienestar, de libertad, de igualdad y de justicia"56. Toda una perspectiva en donde la defensa de la catalanidad y de una vida satisfactoria van necesariamente de la mano del deseo de independencia (lo uno lleva a lo otro y viceversa).

Y en tercer lugar, se muestra una contradicción (tertium non datur) entre nación catalana y España de tal modo que la "permanencia dentro del Estado español"57 imposibilita el desarrollo de la sociedad catalana ya que esto supone la negación de Catalunya como cultura, lengua y tradiciones; algo que ni siquiera la vía autonomista ha sido capaz de corregir, más bien lo ha acentuado. Esto supone que la actual Catalunya, donde hay reconocimiento del catalán y de las tradiciones y cultura catalana a unos niveles muy altos - dentro de su propia historia contemporánea - y siendo uno de los territorios de mayor desarrollo económico en España, no es válida como ejemplo del que partir para la Catalunya que se quiere "fundar"; por eso se afirma rotundamente que "la vía autonomista se ha acabado"s8.

Hablamos, por tanto, de una identidad politica que identifica a Catalunya con la lengua catalana, con una determinada comunidad cultural que tiene una única "voluntad de ser", en donde a quien quiera defender la catalanidad, sentirse como tal, solo le cabe postular la independencia y rechazar la vía autonómica porque esta está muerta. Y a partir de ahí, lo que le corresponde al movimiento social y político es ampliar sus apoyos. Esta concepción sobre la catalanidad responde a una forma determinada de caracterizarla. Cabe defenderla como una identidad más dentro de un contexto amplio y plural, pero tiene no pocos problemas desde un punto de vista democrático si lo que pretende expresar es una identidad politica común de carácter institucional, pues representa solo a una parte de la sociedad catalana. Nos detendremos en dos de estos problemas.

El primero afecta a la manera de entender lo catalán que fusiona una forma de sentirse (catalán) con una opción política (la independencia). Pero resulta que la realidad catalana es más compleja y plural.

Si observamos los datos sobre las identidades en Catalunya se aprecia lo siguiente. La opción "más catalán que español”, que se sitúa a lo largo de estos años en segundo lugar, en octubre de 2012 (28,7\%) cae a la tercera posición y empieza a marcar una tendencia clara a la baja, aunque nunca queda por debajo del 20,9\%. La opción mixta media ("tan catalán como español"), que siempre ha sido la opción mayoritaria en torno a porcentajes del $45 \%$, cae fuertemente a partir de junio de $2012(37,3 \%)$ y se ubica a una distancia ya muy menor respecto de las otras dos opciones perseguidoras. Y la opción de "solo catalán" pasa de ser la tercera opción a adelantar, en octubre de 2012 (29,6 \%), a la opción de "más catalán que español”, manteniéndose en la segunda posición hasta 2017, y siendo su ítem más bajo el $23 \%$ (octubre de 2016) y el más alto el 31,3\% (noviembre de 2013) ${ }^{59}$.

\footnotetext{
55 "La condició de nació va aparellada a la tinença d'un aparell d'Estat”. Ibidem.

56 "Que l'Estat propi és la millor eina per aconseguir majors cotes de benestar, de llibertat, d'igualtat i de justicia”. Ibid., p. 8.

57 "Permanència dins l'Estat espanyol". Ibid., p. 7.

58 "La via autonomista s'ha acabat". Ibidem.

59 “Sentiment de pertinença”, Pregunta C700. Centre d'Estudis d'Opinió (CEO), Baròmetre d'Opinió Politica, 1 onada 2017.
} 
Estos indicadores nos muestran dos cuestiones. Por un lado, es a partir de 2012 cuando se empieza a dar una polarización entre la identidad de "solo catalán" (que sube a costa de la de "más catalán que español") y la "identidad mixta media", la cual a su vez baja en sus porcentajes. Unos datos que coinciden con el estudio cualitativo de Silvina Vázquez sobre las identidades en el que la dicotomización ya ha empezado a cristalizar. Y lo hace sobre dos maneras distintas de definir la identidad política. Así, para determinados sectores independentistas su identidad era robusta, firme y sin ambigüedades ${ }^{60}$, lo que encaja mejor tanto con una identidad clara y no mixta (como la de "solo catalán"), como con la dictomización postulada por la ANC (o dentro o fuera). Sin embargo, para quienes se veían bajo el paraguas catalán y español su identidad se caracterizaba por una expresión más ambivalente ${ }^{61}$, lo que encuentra mejor acomodo en identidades mixtas y en posiciones no dicotómicas.

Por otro lado, las identidades mixtas siguen siendo claramente mayoritarias en relación con las que no lo son de tal modo que su suma se acerca al $70 \%{ }^{62}$. Esto muestra que, pese al ascenso de la identidad de "solo catalán", esta sigue siendo inferior a las mixtas y que solo una incorporación de dicha mixtura será capaz de reflejar la pluralidad de la sociedad catalana, cosa que la identidad política del independentismo, tal y como hemos visto en sus textos, no hace.

En cuanto a la propuesta política que se prefiere de cara a la articulación territorial, se aprecia lo siguiente. Ha sido un rasgo común hasta 2012 que el apoyo a un "Estado independiente" se haya situado siempre por debajo de las opciones "autonomistas" y "federalistas". Sin embargo, a partir de febrero de 2012 la opción por un "Estado independiente" va ascendiendo paulatina y rápidamente hasta un máximo del 48,5\% (noviembre de 2013) y manteniendo una media aproximada del $40 \%{ }^{63}$. Si bien la opción de un "Estado independiente" se mantiene como primera opción desde 2012 hasta 2017, también es verdad que su techo se encuentra en torno a un 48,5\% lo que indica que siendo poderosa no es la mayoritaria, si entendemos por tal superar el $50 \%$.

Esto nos lleva a afirmar que el independentismo a lo largo de este lustro ha "roto" algunas barreras, acercándose a algunos sectores que van más allá de los tradicionalmente independentistas. Si tenemos en cuenta los resultados de las últimas elecciones de 2017, han conseguido ampliar y conservar una masa social y política no pequeña que conforma parte de la realidad catalana y que tiene una traslación desproporcionada - en su favor - desde el punto de vista electoral. Que esto sea así no es de extrañar pues la vocación de ganar a las mayorías ha estado siempre presente en este bloque, y en concreto en la ANC cuando afirma "que haya una mayoría social suficiente de ciudadanos que la quieran" ${ }^{\prime 4}$.

Pero es preciso señalar que en este sentido solo ha conseguido uno de los puntos que el propio movimiento se puso como objetivo para considerar la viabilidad de la independencia ${ }^{65}$ : el referido a la mayoría parlamentaria (en escaños). Por el con-

60 Vázquez, Identidad nacional y autogobierno, p. 23.

61 Ibidem.

62 "Sentiment de pertinença", Pregunta C700. Centre d'Estudis d'Opinió (CEO), Baròmetre d'Opinió Politica, 1 onada 2017.

${ }^{63}$ Pregunta 30, “Creu que Catalunya hauria de ser...”. Centre d'Estudis d'Opinió (CEO), Baròmetre d'Opinió Política, 1 onada 2017.

64 "Que hi hagi una majoria social suficient de ciutadans que la vulguin". Assemblea Nacional Catalana, Full de Ruta 2012, p. 4.

65 Ibidem. 
trario, no ha conseguido ni el reconocimiento internacional anhelado ni la mayoría social suficiente como para llevar a cabo su propósito, no llegando ni al 51 \% de los $\operatorname{votos}^{66}$.

El segundo problema de la reducción de lo catalán a los presupuestos anteriormente indicados tiene un calado mayor, si lo que se pretende es fundar un nuevo país y/o Estado, ya que su definición no incorpora a una parte significativa de la sociedad catalana a la hora de confeccionar su propio proceso deliberativo.

De este modo, se constata un intento de apropiación de lo que es lo catalán en torno a un canon característico de cierto nacionalismo para el que hay una lengua (catalán), una cultura (catalana) y un pueblo (catalán) que conforman una armonía. Se puede calificar de apropiación ya que expresa una mirada parcial que no tiene en cuenta otras sensibilidades ni otras formas de sentirse catalán a la hora de determinar el espacio público en su faceta deliberativa de cara a la decisión que dicha sociedad debería tomar. En ella no encuentran fácil acomodo ideas como que el castellano es una lengua — a la par — de los catalanes y catalanas o que alguien se pueda sentir catalán, incluso sentirse parte de la nación catalana, y no pensar que la vía autonómica, o la federal, estén necesariamente muertas.

Esta parcialidad es un síntoma notorio de falta de pluralismo democrático al no reconocer esa diversidad de identidades a la hora de configurar dicho espacio público deliberativo; es una parcialidad que se apoya en un concepto de nación "objetivizable" que necesariamente conlleva un determinado propósito político (la independencia). Su concepto de nación implica una idea de la sociedad catalana en la que esta $o$ se adecúa al marco previo que dicha idea de nación define $o$ quién no lo haga quedará desplazado del propio proceso deliberativo. De hecho, esa parte de la sociedad que no es independentista no será incluida sustantivamente como sujeto constituyente de la decisión que se quiere tomar (la independencia) para conformar esa voluntad de ser ${ }^{67}$.

La manera en que, de nuevo, esta exclusión se llevará a cabo, desde un punto de vista conceptual y político, será a través del tropo de la sinécdoque. En este caso, la confusión entre la parte y el todo vendrá dada de la siguiente manera: se identificará a la parte independentista de la sociedad catalana con el todo que constituye dicha sociedad de tal modo que el interior constitutivo que forma parte de la plural sociedad catalana quedará no reconocido ni incluido en dicho todo. Es un tipo de sinécdoque que se podría calificar de roussoniana ${ }^{68}$ en la que la caracterización de su voluntad de ser implica una falta de pluralismo democrático notable que le resta legitimidad democrática a dicha propuesta si lo que quiere es alcanzar el fin deseado.

${ }_{66}$ La cuantía para calibrar dicha mayoría se ha ido modificando con el tiempo. En un principio era, inspirándose en Montenegro, más del $50 \%$ de participación y más del $55 \%$ de los votos afirmativos (ibidem). Al final del procés se quedó solo en más votos afirmativos que negativos tal y como recogía el artículo 4.4 de la Ley de Referéndum de septiembre de 2017. Véase LLEI 19/2017, del 6 de setembre, del "Refèrendum d'autodeterminació": Diari Oficial de la Generalitat de Catalunya, Barcelona, 2017.

Para una reflexión sobre una mayoría suficiente, véase Alberto López Basaguren, "Demanda de secesión en Cataluña y sistema democrático. El procés a la luz de la experiencia comparada": Teoría y realidad constitucional, n. 37 (2016), pp. 163-185.

${ }^{67}$ Sí lo será formalmente al reconocerle su derecho a voto antes y después de haberse constituido la "república catalana". Véase AA. VV., Libro Blanco de la Transición Nacional de Cataluña. Síntesis, Generalitat de Catalunya, Barcelona, 2014.

68 Véase María José Villaverde, "Un conservador en el Siglo de las Luces: Jean-Jacques Rousseau”: Revista de Estudios Políticos, n. ${ }^{\circ} 58$ (1987), pp. 243-266. 
En el análisis de los textos de la ANC ya se han expuesto algunos ejemplos en los que no se considera a esa parte de la sociedad catalana que no es independentista. Pero hay dos momentos cúlmenes políticos que ejemplifican esta concepción y que afectan ya no solo a los orígenes del movimiento social y político, sino a su etapa final.

El primero de ellos es lo ocurrido el mismo día 1 de octubre de 2017 tras lo acontecido ese día. Los errores cometidos por la desproporcionada carga policial en esa lúgubre mañana fueron indudables. Así mismo, el 1 de octubre fue un importante acto de movilización social. Pero dichas verdades no conllevan que la votación celebrada el 1 de octubre, más allá de su ilegalidad, fuera un acto legítimo ni vinculante como para tomar decisión alguna democrática a este respecto; de hecho, no fue legitimado como referéndum ni consulta democrática por más de la mitad de la ciudadanía catalana.

De esto se hizo eco Vicenç Fisas cuando afirmaba en diciembre de 2017 que "ya advertí de lo que pasaría si se declaraba una DUI sin el apoyo de una amplísima mayoría (mínimo de dos tercios); y dije que un referéndum declarado ilegal por el Estado, en el que no se sentirían interpelados los partidarios del no - la inmensa mayoría de los cuales no participarían-, no tendría validez en la medida en que no reflejaría lo que pensaba toda la población catalana, sin excepciones" ${ }^{\prime 6}$.

Y sin embargo, la respuesta del independentismo catalán a ese no sentirse interpelado fue la de asumir y dar validez a los resultados del 1 de octubre como si estos fueran la expresión legítima y democrática de la sociedad catalana lo que permitía automáticamente proclamar la independencia.

La misma noche del 1 de octubre con todo el govern a su espalda, Carles Puigdemont afirmaba que "ahora que hemos conseguido celebrar el referéndum de autodeterminación...Las instituciones catalanas tienen el deber de respetar e implementar lo que hoy han decidido sus ciudadanos...Los ciudadanos de Catalunya nos hemos ganado el derecho a tener un Estado independiente que se constituya en forma de República. En consecuencia el Govern que presido trasladará en los próximos días al Parlament de Catalunya... los resultados de la jornada de hoy para que actúe de acuerdo con aquello previsto en la Ley de Referéndum"70.

Y diez días mas tarde, en la sesión donde anunciará la DUI, y tras una introducción un tanto más amplia donde apelaba al conjunto de la ciudadanía catalana, Puigdemont acotó para lo que realmente había ido al Parlament: "Hoy toca hablar de los resultados del 1 de octubre en el Parlamento y eso es lo que haremos...Estamos aquí porque el pasado día 1 de octubre Cataluña celebró el referéndum de autodeterminación" "71. Después de hacer una comparación con los resultados del estatut, de

69 "Ja vaig advertir del que passaria si es declarava una DUI sense el suport d'una amplíssima majoria (mínim de dos terços); i vaig dir que un referèndum declarat il·legal per l'Estat, en el qual no se sentirien interpel·lats els partidaris del no - la immensa majoria dels quals no hi participaria-, no tindria validesa en la mesura que no reflectiria el que pensava tota la població catalana, sense excepcions". Vicenç Fisas, "El temps i el mètode en la política catalana": Ara.cat (28-12-2017). Disponible en: https://www.ara.cat/opinio/vicenc-fisas-temps-metodepolitica-catalana_0_1933006688.html (1-3-2018). La reflexión de Fisas constata la pluralidad de opiniones que hay dentro del independentismo, como es su caso.

70 Carles Puigdemont, "Declaración íntegra del President", en Marta Lasalas, "Puigdemont llevará al Parlament la declaración de independencia": El Nacional.cat (1-10-2017). Disponible en: https:/www.elnacional.cat/es/ politica/puigdemont-parlament-declaracion-independencia-referendum_197643_102.html (1-3-2018).

71 Carles Puigdemont, "Mensaje íntegro de la comparecencia del President Puigdemont ante el pleno del Parlament": Madridiario (10-10-2017). Disponible en:

https://www.madridiario.es/449161/discurso-mensaje-comparecencia-puigdemont (1-3-2018). 
defender la fiabilidad y operatividad del censo, así como de mostrar reconocimiento "a los votantes del Sí y los del No, y a los del voto en blanco"72, insistió en que "con los resultados del referéndum del 1 de octubre Cataluña se ha ganado el derecho a ser un Estado independiente" "73. Y una vez que había suspendido dicha declaración se comprometió en "avanzar en las demandas del pueblo de Cataluña a partir de los resultados del 1 de octubre" $"$.

En ambos casos se detecta claramente cómo los resultados del 1 de octubre tenían para Puigdemont - aunque no solo para él, pues todos los líderes independentistas formularon sentencias similares - plena legitimidad democrática como para hablar por el conjunto de la sociedad catalana y representarla. Ahí quedaron en evidencia los déficits democráticos de su propia concepción puesto que tal "voluntad colectiva de ser" ${ }^{\text {"75 }}$ representaba solo a una parte de Catalunya obviando la dimensión plural, y pluralista, de la sociedad catalana, de ahí que dicho planteamiento no conforme una identidad política común, sino una parcial al representar solo a una parte insuficiente como para pretender expresar el todo. Este es el problema democrático en el que se encuentra el actual independentismo catalán y que no ha podido resolver pese a su empeño por agrandar su base social y política. Y al quedar, tal y como hemos visto con anterioridad, esta identidad parcial definida de manera dicotómica, lo que hace es alimentar la división social ${ }^{76}$ y la polarización abriendo una sima en el seno de la sociedad catalana, pudiéndose hablar, como hace Basaguren, de dos naciones dentro de Catalunya ${ }^{77}$. El peso de determinados elementos identitarios dicotómicos genera serias dificultades en el independentismo como para mirar a aquellos catalanes y aquellas catalanas que no quedan reflejadas en su concepción.

Y desde un punto de vista sociológico también se confirma esta separación entre ambos mundos. En este sentido se expresaba un estudio que mostraba cómo el sentimiento independentista no había sido capaz de penetrar en la otra mitad de la sociedad catalana, conformándose dos realidades que se mueven en paralelo ${ }^{78}$. Una dimensión no inclusiva de dicha identidad independentista que tendrá, como contrapartida, cierta expresión político-social en la manifestación del 8 de octubre de 2017 (y en la del 29 del mismo mes) celebrada en Barcelona, la cual hará visible colectivamente a una parte de la ciudadanía catalana que no ha contado en nada para este procés $s^{79}$.

Pero los problemas normativos de esta identidad parcial no acaban aquí. Queda por plantear qué tipo de relación se da entre esa parte de la sociedad catalana que no

\footnotetext{
Ibidem.

Ibid., p. 5.

Ibidem.

Assemblea Nacional Catalana, Full de Ruta 2013, p. 3.

${ }^{76}$ En 2014 Stéphane Dion ya advertía de esta posibilidad cuando señalaba que: "un eventual referéndum de autodeterminación en Catalunya podría comportar ciertos peligros y sería un 'traumatismo social' porque no solo separaría a Catalunya de España, sino también a los mismos catalanes... Todo referéndum secesionista es un 'traumatismo social' porque unos quieren quitar a otros su sueño, mientras que otros a uno su conciudadanía". Stéphane Dion, "Un referéndum de autodeterminación es un traumatismo social": La Vanguardia (10-3-2014). Disponible en: https://www.lavanguardia.com/politica/20140310/54402966310/stephane-dion-un-referendumde-autodeterminacion-es-un-traumatismo-social.html (1-3-2018).

77 Basaguren, "Hablemos (de nuevo) de nación".

78 Grupo OEC, "La Cataluña inmune al procés", Barcelona, 20 de abril de 2017. Disponible en: https://www.societatcivilcatalana.cat/sites/default/files/docs/La-Cataluna-inmune-vf.pdf (1-3-2018).

79 Iñaki Gabilondo, "Ya estamos todos despiertos": El País (9-10-2017). Disponible en: https://elpais.com/elpais/2017/10/09/la_voz_de_inaki/1507532368_744982.html (1-3-2018).
} 
forma parte de dicha identidad y el "adversario" del que se ha hablado en apartados anteriores.

Para llevar a cabo esa relación el tropo que es preciso analizar es el de la metáfo$\mathrm{ra}$. Una metáfora supone establecer una relación de identificación entre dos términos (o entidades) entre los que hay alguna - y por tanto no completa - semejanza. Toda metáfora tiene tres componentes que son: el primer y segundo término de la comparación y la supuesta cualidad común. Puede que estos tres elementos no siempre aparezcan de forma explícita, no pudiendo faltar el segundo término de la comparación; cuando solo aparece este la metáfora será calificada de implícita.

En el caso que nos ocupa, este segundo término es el de la España irreformable; el primer término es la sociedad catalana no independentista y la cualidad común el no sentirse "solo catalán" (o para ser más preciso: no sentirse independentista). La metáfora implícita de la España irreformable supondrá una identificación de esta con la sociedad catalana no independentista de tal modo que esta quedará subsumida en lo que esta metáfora contiene: autoritarismo, petrificación, inmovilismo, anticatalanismo, etc.

La identificación que se establece entre la España irreformable —el exterior constitutivo que se nombra y "contra el que se está"- y la parte de Catalunya no independentista - el interior constitutivo que no se nombra y que no se incluyehace que ese sector de la sociedad catalana difícilmente pueda ser reconocido como parte de la identidad política del actual independentismo catalán puesto que queda situado tan fuera como supuestamente lo está el exterior constitutivo. Una identificación que recorre gran parte de las Hojas de Ruta en las que se aborda dicha cuestión - sin prácticamente modificación alguna sobre este menester- en donde la manera habitual de acercarse a esa parte de la sociedad catalana es casi ni nombrarla ${ }^{80}$. Un tropo metafórico que conlleva todo un ejercicio de exclusiones que en nada ayuda a la formulación democrática y pluralista de dicha identidad política, expresando una concepción homogénea y sesgada de la sociedad catalana.

Esta identificación entre ambas realidades no solo tiene efectos narrativos, sino también cierto reflejo social. Belén Barreiro se ha referido a esta identificación en un estudio que hizo para MyWord en noviembre de 2017 y que ejemplifica bien este tropo metafórico. Con el discurrir del tiempo, antes no era así, y sobre todo en el último año, "se constata la división en dos bloques de la sociedad catalana... Ahora hay una mitad de la sociedad catalana que es igual que la española"\$1 conformándose dos sociedades: "la de los catalanes no independentistas junto con el resto de españoles frente a los catalanes independentistas" ${ }^{2}$. Y a esa parte de la sociedad catalana no independentista no se dirigen ni los políticos no independentistas "ni sobre todo los políticos independentistas" 83 .

Ya analicemos su relato o atendamos a otros estudios sobre la pervivencia de ciertos ítems en la ciudadanía catalana, se constata que el independentismo actual tiene un muro que no ha podido asaltar y que difícilmente lo podrá hacer mientras su identidad política tenga por motor la no inclusión de una parte de Catalunya y,

\footnotetext{
80 Assemblea Nacional Catalana, Full de Ruta 2012, p. 4.

81 "En Cataluña vemos dos sociedades: la de los independentistas y la de los no independentistas". Belén Barreiro en el programa "Hoy por hoy": Cadena SER (23-11-2017). Podcast y transcripción disponibles en: http://play.cadenaser.com/audio/001RD010000004808159/?leer=on (1-3-2018).

82 Ibidem.

83 Ibidem.
} 
a la vez, la esencialización de España como realidad irreformable. El irreformable esencialismo que proyecta sobre España es directamente proporcional a la falta de escucha que tiene sobre la otra Catalunya que no nombra porque - como sujeto constituyente - queda fuera de su identidad politica no siendo necesaria su participación en su proceso deliberativo. De este modo, la dicotomía que se formula entre España vs Catalunya, se traslada hacia dentro de la propia sociedad catalana siendo, ahora, una dicotomía interior ${ }^{84}$.

\section{Afectos democráticos y política de abandonos}

Es esta metáfora la que completa el proceder por el cual la identidad política independentista saca fuera del proceso deliberativo de su proyecto político a una parte significativa de la sociedad catalana, lo cual afecta no solo a sus resultados, sino a la matriz retórica y conceptual desde la que se piensa dicha realidad. Una matriz de falta de pluralismo e inclusividad, y por tanto de democracia, que viene cargada de creencias, pero también de ciertas emociones que, relacionadas con estas, quedan desplazadas en esta concepción.

A la hora de pensar la relación entre afectos y creencias políticas una pregunta importante que hay que responder, desde el punto de vista democrático, es la de "qué sentimientos, qué afectos resultan pertinentes para la deliberación política" 85 .

A lo largo de todo el procés, e incluso antes si levantamos la vista más allá de Catalunya y se observa la realidad política española, se detectan toda una serie de emociones que van emergiendo y que juegan un papel muy importante en su desarro1lo. Suele ser común afirmar que en el actual independentismo catalán hay mucho de emocional (y por añadidura poco de racional). Cuando tal propósito pretende señalar la "actitud mítica" 86 , visceral y semi-religiosa que en muchos momentos lo acompaña es una disyuntiva atinada. Pero si se quiere profundizar algo más, es necesario hacer una aproximación más honda. Es deseable pararse a pensar ${ }^{87}$.

El enfoque teórico que hemos tomado en este artículo permite desplegar una perspectiva más compleja. No solo porque establece relaciones entre ciertas pasiones y ciertas creencias y/o pensamientos, sino también porque pretende analizar en concreto qué emociones se ponen en juego y cuáles no - y cómo-, no haciendo un uso abstracto de las mismas.

Cuando en 2010 se abrió una estructura de oportunidades politicas tras la acumulación de diferentes malestares que generaron una insatisfacción con el proceso autonómico, se abrió un campo emocional que venía caracterizado por una indignación. Esta estaba justificada en tanto en cuanto había unos objetos determinados

${ }^{84}$ Ni España es igual a esta caricatura homogénea, ni Cataluña a la que se pretende hacer desde otros lares. Ambas son realidades sociales y culturales complejas, plurales y contradictorias.

85 Máiz, "La hazaña de la razón”, p. 41.

86 Manuel García-Pelayo, Los mitos políticos, Madrid, Alianza, 1986, pp. 26 y ss. Son atinadas las palabras de Francis Bacon (1561-1626) cuando criticaba duramente a quienes "hacen leyes imaginarias para repúblicas imaginarias, y sus discursos son como estrellas, que dan poca luz porque están tan altas" (citado en Roiz, $L a$ recuperación del buen juicio, p. 32). Palabras de inicios del siglo diecisiete que parecen haber sido escritas hace unos meses.

87 Lo dicho en este apartado sobre las emociones sirve también para explicar parte del comportamiento de otras formaciones políticas de ámbito estatal, en concreto aquellas que están en el gobierno central, actuando muchas veces como vasos comunicantes. 
(crisis política, territorial, económica, etc) que la causaba y hacia los que esta se dirigía de tal modo que se pensaba que lo que estaba ocurriendo era injusto. Esta indignación era una emoción de una profunda transversalidad, tal y como se apreció en diferentes momentos, que abarcaba una variedad enorme de sensibilidades políticas y sociales. La indignación es, como señala Nussbaum, uno de los afectos democráticos más característicos ya que ayuda a reforzar la reivindicación democrática contra la injusticia.

Es verdad que ante esta indignación habría sido preciso dar respuesta en el sentido planteado por Quintiliano, es decir, de una mano abierta con capacidad para conectar con dicha insatisfacción hondamente sentida; y hacerlo de tal manera que nuestra democracia se ampliara. Tal cosa no se dio ni por parte de los actores políticos catalanes ni de las formaciones políticas del conjunto del país. En el gobierno español primó un quietismo político, atrincherado en un positivismo jurídico radical - alargado en el tiempo_- que expresaba indolencia ante dicho malestar. Por el contrario, sí hubo una parte de la sociedad y de la política catalana que ante esa insatisfacción reaccionó de una forma activa; reacción que fue la que dio pie al nacimiento del actual independentismo catalán.

La primera emoción que se puede detectar en la propuesta llevada a cabo por los sectores independentistas fue reinterpretar lo que era una situación de insatisfacción e indignación cargada de agravio, ampliamente compartida por la sociedad catalana, a otra en términos de "humillación al pueblo catalán". Si como hemos visto la indignación es necesaria para el buen ejercicio de la democracia, la humillación no cabe en esta (cuando se da indica algo insoportable para la democracia). Este cambio fue incorporado como tal en el relato político del independentismo. Esto supuso una lectura intensiva del malestar y, a la vez, una tergiversación y reducción del mismo —en cuanto a su amplitud - pues no todos — ni gran parte - de quienes criticaban, por ejemplo, la sentencia del Tribunal Constitucional se identificaban con dicha emoción y menos aún con el deseo de crear un Estado propio ${ }^{88}$.

Del mismo modo definir un adversario tan marcadamente negativo como es el de la España irreformable (sinónima de autoritaria, centralista, no democrática, antigua, etc.) que, a su vez, quedaba identificado con una parte de la sociedad catalana, tenía el riesgo de hacer emerger otra de las emociones a desterrar en un sistema democrático. Si alguien queda identificado con un juicio tan negativo que afecta a su identidad política y cultural por el hecho de posicionarse en contra de, y frente a, posturas independentistas, y si esta identificación además lleva el aval de la institución política y de la corriente política hegemónica como es el nacionalismo catalán, ¿cuál es la emoción que probablemente florecerá? ¿No cabe pensar que pueda sentirse vergüenza por situarse en dicho planteamiento ante la presión existente? Y si fuera así, ¿en qué medida dicho sentimiento supondría socavar su fuente democrática?

Una sociedad democrática tiene razones poderosas para sentirse incómoda respecto de la vergüenza debido a la gran importancia que atribuye al valor igualitario entre las personas y a nociones relacionadas con el respeto hacia uno mismo y los otros. Sin embargo, la vergüenza tiene "un vínculo íntimo con la jerarquía social y con una cultura pública que expresa la creencia de que las personas son desiguales en cuanto a su valor" $"$.

\footnotetext{
88 Véase Antón Costas, El final del desconcierto, Península, Barcelona, 2017, pp. 289 y ss.

89 Martha Nussbaum, El ocultamiento de lo humano, Katz, Buenos Aires, 2006, p. 385.
} 
Con todo, la emoción que más brilló por su ausencia en la identidad política independentista fue la falta de compasión (o simpatía) democrática y de empatía. La articulación de la identidad política independentista como una identidad política parcial que no escuchaba a la otra parte de la sociedad catalana supuso la ausencia de una actitud compasiva y empática para con quienes ni se nombra.

La empatía es "la capacidad de imaginar la situación del otro, tomando con ello la perspectiva de ese otro... Requiere de nosotros que nos introduzcamos en el problema o la dificultad del otro, y eso precisa, a su vez, tanto una distinción entre el yo/nosotros y el otro, como un desplazamiento imaginativo" ${ }^{\text {". }}$. Es una experiencia que requiere de una imaginación vivaz del otro que no forma parte de mi grupo. En sentido estricto, no es sinónima de compasión y forma parte del debate filosófico si es necesaria para esta o no, aunque cuanto menos es de "una gran ayuda para la compasión" "91. Pero ya forme parte de la compasión o no, la empatía, en la concepción de la identidad política del actual independentismo catalán, tal y como hemos venido explicando a lo largo de estas páginas, no estuvo presente a la hora de imaginar al otro desde el momento en que no se tiene en cuenta — siendo indiferente, que es el antónimo de empatía - a aquella parte de la sociedad catalana que de algún modo se tendría que representar. Estuvo presente entre los propios - los unos diría Todorov- pero no entre los "extraños" — los otros, al decir de este mismo autor-.

Algo similar ocurrirá con la compasión. La compasión (o simpatía) es "una emoción dolorosa orientada hacia el sufrimiento grave de otra criatura o criaturas" $" 92$. Esta viene caracterizada por varios elementos. Supone reconocer gravedad en el sentimiento ajeno, es decir, que "la persona que siente esa emoción piensa que otra está sufriendo de un modo importante y no trivial"93. También significa que el padecimiento del otro - por ejemplo la posible angustia de no verse representado en las decisiones que se iban tomando de cara a la Declaración Unilateral de Independencia - no es culpa suya. Y, por último, requiere un razonamiento eudonómico, esto es, un juicio que "sitúa a la persona o personas que sufren entre las partes importantes de la vida de la persona que siente la emoción compasiva" $"$. Es decir, supone reconocer que quien padece no es culpable de tal situación y que se valora como importante lo que el otro siente y que eso es importante para uno mismo.

Sin embargo, poco de esto emergió en el discurso público de dicha identidad política. Igual sí se pensaba en el ámbito privado, pero no formó parte del espacio público democrático ni del proceso deliberativo en la toma de ciertas decisiones que comprometían a otras personas y a sus destinos. Los concretos ejercicios de sinécdoque y metáfora llevados a cabo no ayudaron a que esta emoción floreciera de cara a los otros, aunque sí lo hiciera, de nuevo, entre los propios.

Cuando se identifica a una parte de la sociedad catalana o a una sociedad entera (España) con lo hecho por su gobierno o sus representantes - los cuales son los causantes del mal - difícil es que emerja una idea de no culpabilidad hacia esa población, aunque sea en el ámbito de lo no consciente; cuando se confunde la parte con el todo del modo en el que se hizo no reconociendo al interior constitutivo de

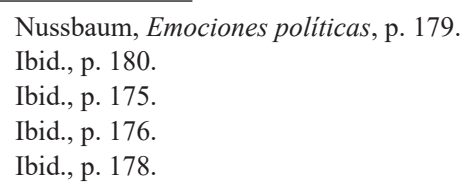


la sociedad catalana, difícil es que se pueda pensar que lo que el otro siente es importante ya que el pensamiento eudaimonista (me importa lo que te importa) está ausente. Lo que hay es indiferencia e insensibilidad, los antónimos justamente de la compasión, como señalábamos más arriba. Y cuando esta no se da puede terminar ocurriendo que se convierta "en extranjeros a tus conciudadanos" la división social.

Esta forma de definir la identidad politica por parte del actual independentismo catalán — falta de inclusión y pluralismo - lo que suele conllevar es la emergencia de cierto narcisismo ${ }^{96}$, el cual choca con la experiencia compasiva y empática, aunque, por el contrario, sí es perfectamente compatible con la pietà.

Esta falta de empatía y compasión hacia las otras maneras de sentirse parte de una sociedad plantea problemas especiales si se aspira a la igual dignidad de todas las formas de identificación que se pueden dar dentro de una ciudadanía; problemas que deben abordarse "no solo mediante la aplicación de reglas que promuevan esa igualdad de respeto, sino también por medio del juego y de la simpatía imaginativa, en un ejercicio que incluya la vulnerabilidad y la disposición a renunciar a la omnipotencia"97.

Así, la forma en la que la identidad política independentista catalana se fraguó produjo una "política de abandono"98 hacia una parte muy significativa de la sociedad catalana que es preciso destacar por su déficit democrático; abandono, huecos emocionales, que tampoco la otra parte en controversia rellenó. Y es que las carencias afectivas señaladas también estuvieron presentes — desde el punto de vista del discurso público - en aquellas formaciones políticas del conjunto del país —a la cabeza de todas, el gobierno español- que debían responder satisfactoriamente ante tales demandas y tampoco lo hicieron. Tales indolencias no ayudaron a reforzar los lazos afectivos entre diferentes que son tan necesarios, según la perspectiva teórica planteada, para el buen funcionamiento de la democracia; más bien los congeló. En este vacío emocional de empatía y compasión los errores fueron compartidos. Y sus posibles consecuencias sociales repercutirán sobre el conjunto de la sociedad catalana.

Como dice Roiz, "empieza a echarse en falta una democracia pacífica, trabajadora y cotidiana, con sitio para hombres, mujeres e infantes, que cuide con garantías aquí y ahora de nuestras vidas, y que no inhiba ni anule nuestra espiritualidad"99.

\section{Concluyendo}

Tras este recorrido, se puede concluir con que el déficit democrático de la propuesta independentista no afecta solo a su legalidad. Es cierto que este aspecto cobró protagonismo a partir de septiembre de 2017, ante lo cual conviene recordar la considera-

\footnotetext{
95 Stéphane Dion, "Entrevista": El País (25-11-2003). Disponible en: https://elpais.com/diario/2003/11/25/espana/1069714810_850215.html (1-3-2018).

96 Entendemos por narcisismo "cuando las personas se centran egoístamente en su propia seguridad y satisfacción e ignoran la de los otros". Nussbaum, Emociones politicas, p. 210.

97 Nussbaum, Emociones políticas, p. 231.

98 Roiz, La recuperación del buen juicio, p. 13.

99 Ibid., p. 41.
} 
ción que hizo Dion cuando afirmaba que "la democracia y el principio de legalidad son inseparables" 100 .

Tampoco su déficit se encuentra solo en la cantidad de apoyo recabado. Es verdad que el movimiento independentista afirma su vocación mayoritaria. Pero a día de hoy no llega ni al $50 \%$, ni a otros porcentajes mayores y más deseables para abordar una cuestión tan relevante como la que se plantea. Este hecho hace que no tenga legitimidad democrática para imponer sus planteamientos al conjunto de la sociedad catalana.

También es cierto que ha obtenido reiterados resultados a lo largo de este lustro, los suficientes como para formar legítimamente un govern y para que cualquier solución política pase por tener en cuenta dicha realidad ${ }^{101}$, a la par que la otra parte también debe ser escuchada porque, de lo contrario, no habrá solución democrática viable.

Pero estos dos problemas no son los únicos que hay puestos encima de la mesa. Hay otro, que es el que se ha pretendido abordar en este artículo, de carácter teórico y normativo, que es previo y motiva el de índole práctica, que afecta a la definición de su identidad política. Y lo hace de tal modo que si fueran fieles a la identidad política del país que defienden ocurriría que solo cabría una parte de la sociedad catalana en ella, lo que refleja déficits y serias debilidades democráticas en su formulación por su falta de pluralismo e inclusión; debilidades que afectan también a su escasa fortaleza emocional democrática, pues ni la empatía ni la compasión (simpatía) con los otros - dos de los afectos cruciales para una buena democracia — hacen acto de presencia en su identidad política ${ }^{102}$.

Por todo ello, cabe afirmar que la identidad política propuesta por el actual movimiento independentista catalán es un identidad política parcial y particular y no una identidad política común y pluralista y, por tanto, sin el suficiente fundamento democrático como para llevar a cabo su propósito.

Por el contrario, una identidad política común y pluralista supondría crear un tipo de identidad nueva, de carácter transversal, que una a partes diferentes en aras de un proyecto inclusivo y plural de país. Una identidad política que si quiere ser democráticamente sostenible debería ser capaz de expresar los sentidos éticos y emocionales de una parte realmente significativa de la sociedad ${ }^{103}$. Y es que la democracia no es solo una cuestión de apoyos y procedimientos legales, que también, sino de valores y concepciones normativas.

\section{Referencias bibliográficas}

AA. VV., Libro Blanco de la Transición Nacional de Cataluña. Síntesis, Generalitat de Catalunya, Barcelona, 2014.

100 Stéphane Dion, "La democracia y el principio de legalidad son inseparables": El País (22-7-2017). Disponible en: https://elpais.com/politica/2017/07/22/actualidad/1500733917_804383.html (1-3-2018).

101 Como afirma Santiago Muñoz Machado, "hay que dialogar y negociar, pero nadie se querrá sentar al otro lado de la mesa mientras no se pueda emplear un lenguaje inteligible, se reduzca la tensión social inducida y se reponga la lealtad a las leyes. [Cuando esto ocurra] podrán culpar con más razón al Gobierno del Estado de su insoportable indolencia". Santiago Muñoz Machado, "Anomia catalana": La Vanguardia (10-2-2018). Disponible en: https://www.lavanguardia.com/opinion/20180210/44652016033/anomia-catalana.html (1-3-2018).

102 Debilidades que nos permiten decir que dicha identidad politica es expresión de un razonamiento dialéctico que hace un uso lesivo de ciertos tropos retóricos.

103 Lo cual significaría traspasar, en la sociedad catalana, las fronteras de uno u otro bloque y/o espacio político. 
Álvarez Junco, José, Mater dolorosa, Taurus, Madrid, 2017.

Álvarez, Javier, "Entrevista": eldiario.es (14-11-2017). Disponible en: https://www.eldiario.es/politica/dirigentes-independentistas-barbaridades-conducta-rebelion_0_707980198.html (1-3-2018).

Assemblea Nacional Catalana, Declaració de la Conferèrencia Nacional per l'Estat propi, Barcelona, 30 de abril de 2011. Disponible en: https://assemblea.cat/index.php/documents/ (15-9-2018).

—, Full de Ruta 2012: Línies estratègiques i propostes d'actuació, Barcelona, 10 de marzo de 2012. Disponible en: Disponible en: http://ipaz.ugr.es/wp-content/uploads/2018/05/3.Full-de-Ruta-2012-marzo-10..pdf (1-3-2017).

—, Full de Ruta 2013: Full de Ruta aprovat en l'Assemblea General del 16 de març de 2013, Girona, 16 de marzo de 2013.

—, Assemblea General ordinaria 2015. Ponència Marc (2015-2016), Lleida, 12 de abril de 2015.

Barreiro, Belén, "Hoy por hoy": Cadena SER (23-11-2017). Podcast y transcripción disponibles en: http://play.cadenaser.com/audio/001RD010000004808159/?leer=on (1-3-2018).

Basaguren, Alberto López, "Demanda de secesión en Cataluña y sistema democrático. El procés a la luz de la experiencia comparada": Teoría y realidad constitucional, n. ${ }^{\circ} 37$ (2016), pp. 163-185.

Bobbio, Norberto, The future of Democracy, Polity Press, Cambridge, 1987

Centre d'Estudis d'Opinió, Baròmetre d'Opinió Politica, 1 onada 2017, Generalitat de Catalunya, Barcelona, 2017. Disponible en:

http://ceo.gencat.cat/ca/barometre/detall/index.html?id=6168 (1-3-2018).

Costas, Antón, El final del desconcierto, Península, Barcelona, 2017.

Díaz, Elías, "Legitimidad democrática versus legitimidad positivista y legitimidad iusnaturalista", en AA. VV, Anuario de Derechos Humanos, n. ${ }^{\circ}$ 1, Universidad Complutense de Madrid, Madrid,1981.

Dion, Stéphane, "Entrevista”: El País (25-11-2003). Disponible en: https://elpais.com/diario/2003/11/25/espana/1069714810_850215.html (1-3-2018).

_, "Un referéndum de autodeterminación es un traumatismo social": La Vanguardia (10-32014). Disponible en:

www.lavanguardia.com/politica/20140310/54402966310/stephane-dion-un-referendum-de-autodeterminacion-es-un-traumatismo-social.html (1-3-2018).

_ , "La democracia y el principio de legalidad son inseparables": El País (22-7-2017). Disponible en:

https://elpais.com/politica/2017/07/22/actualidad/1500733917_804383.html (1-3-2018).

Fernández-Llebrez, Fernando, "Democratización de las identidades, transgenerismo y malestares de género": Desafíos, vol. 27, n. ${ }^{\circ} 2$ (2015), pp. 99-143.

Fisas, Vicenç, "El temps i el mètode en la política catalana": Ara.cat (28-12-2017). Disponible en:

https://www.ara.cat/opinio/vicenc-fisas-temps-metode-politica-catalana_0_1933006688. html (1-3-2018).

Gabilondo, Iñaki, "Ya estamos todos despiertos": El País (9-10-2017). Disponible en https:/elpais.com/elpais/2017/10/09/la_voz_de_inaki/1507532368_744982.html (1-32018).

García Rovira, Anna Ma (ed.), España, ¿nación de naciones?, Serie Ayer, 35, Marcial Pons, Madrid, 1999. 
Generalitat de Catalunya, LLEI 19/2017, del 6 de setembre, del "Refèrendum d'autodeterminació": Diari Oficial de la Generalitat de Catalunya, Barcelona, 2017.

Graupera, Jordi, "El desbordamiento": El Nacional.cat (17-2-2018). Disponible en: https:// www.elnacional.cat/es/opinion/jordi-grauper-el-desbordamiento_240057_102.html (1-32018).

Grupo OEC, "La Cataluña inmune al procés”, Barcelona, 20 de abril de 2017. Disponible en: https:/www.societatcivilcatalana.cat/sites/default/files/docs/La-Cataluna-inmune-vf. pdf (1-3-2018).

Juaristi, Jon, "Identidad política y política de identidades": Letras libres, n. ${ }^{\circ} 5$ (2002), pp. 40-45.

Juliana, Enric, "La España de los pingüinos": La Vanguardia (8-10-2017). Disponible en: https:/www.lavanguardia.com/opinion/20171008/431878716908/la-espana-de-los-pinguinos.html (1-3-2018).

López Basaguren, Alberto, “Hablemos (de nuevo) de nación”: El Correo (27-11-2016), p. 2. Disponible en: http://www.pensamientocritico.org/alblop1216.pdf (15-9-2018).

Máiz, Ramón, "La hazaña de la razón: la exclusión fundacional de las emociones en la teoría política moderna": Revista de Estudios Políticos, n. ${ }^{\circ} 149$ (2010), pp. 11-45.

Muñoz Machado, Santiago, Informe sobre España, Crítica, Barcelona, 2014.

_, "Anomia catalana": La Vanguardia (10-2-2018). Disponible en: www.lavanguardia.com/opinion/20180210/44652016033/anomia-catalana.html (1-3-2018).

Muñoz, Jordi, La construcción política de la identidad española, CIS, Madrid, 2013.

Nussbaum, Martha, El ocultamiento de lo humano, Katz, Buenos Aires, 2006.

— , Emociones politicas, Paidós, Barcelona, 2014.

Puigdemont, Carles, "Declaración íntegra del President”, en Marta Lasalas, "Puigdemont llevará al Parlament la declaración de independencia": El Nacional.cat (1-10-2017). Disponible en: https://www.elnacional.cat/es/politica/puigdemont-parlament-declaracion-independencia-referendum_197643_102.html (1-3-2018).

_, "Mensaje íntegro de la comparecencia del President Puigdemont ante el pleno del Parlament": Madridiario (10-10-2017). Disponible en: https:/www.madridiario.es/449161/discurso-mensaje-comparecencia-puigdemont (1-3-2018).

Quintiliano de Calahorra, Obra completa, Universidad Pontificia de Salamanca, Salamanca, 1996.

Roiz, Javier, La recuperación del bien juicio. Teoría política en el siglo veinte, Editorial Foro Interno, Madrid, 2003.

Sánchez-Cuenca, Ignacio, La confusión nacional. La democracia española ante la crisis catalana, Los Libros de la Catarata, Madrid, 2018.

Todorov, Tzvetan, Los enemigos íntimos de la democracia, Galaxia Gutenberg, Madrid, 2012.

Vázquez, Silvina, Identidad nacional y autogobierno. Un estudio cualitativo sobre las configuraciones identitarias nacionales en la Cataluña contemporánea, Monografies, Centre d'Estudis d'Opinió (CEO), Generalitat de Catalunya, Barcelona, Julio 2013.

Villaverde, María José, "Un conservador en el Siglo de las Luces: Jean-Jacques Rousseau": Revista de Estudios Politicos, n. ${ }^{\circ} 58$ (1987), pp. 243-266.

Walzer, Michael, Pensar politicamente, Paidós, Barcelona, 2010. 